\title{
The Study on the Attribution of Urbanization Mass Incidents in China's West National Areas
}

\author{
-based on the Grounded Theory
}

\author{
Yiting Luo \\ International Business School \\ Yunnan University of Finance and Economics \\ Kunming, China \\ 372402411@qq.com \\ Ying Yang* \\ International Business School
}

\author{
Yunnan University of Finance and Economics \\ Kunming, China \\ 11476423@qq.com \\ Xinqi Zhang \\ Business School \\ Yunnan University of Finance and Economics \\ Kunming, China \\ 732865022@qq.com
}

\begin{abstract}
Because of the unique geographical location and religious custom of Western National Areas, it appears that the group events occurred in urbanization have special status. Informal institution, like sense of family, religion, culture and so on, will take up a large proportion. Based on the collecting, coding, clustering the information about some typical cases in recent years of Urbanization Mass Incidents in western national regions by grounded theory. Then get 8 reasons, including Trigger Events and so on. At last, build reasons conceptual model, which can provide a theoretical basis and guide to action for the relevant departments to solve similar group events.
\end{abstract}

Keywords-West National Areas; Urbanization Mass Incidents; The key factors; Grounded Theory

\section{INTRODUCTION}

\section{A. Reality Background}

Urbanization develops rapidly in China and the urbanization rate has reached $56.1 \%$ in 2015. However, urbanization caused more and more group conflict events. According to the data of Social Blue Book of 2013, in 2012, the amount of group conflict events resulted by land acquisition, demolition and environmental problems, accounted for about $66.6 \%$ of all conflicts.

The western region in China has 12 provinces, municipalities and autonomous regions, with 46 major ethnic minorities. In 2010, the census shows that Midwest Minority Population accounts for $71.42 \%$ of the national minority population. In the process of promoting urbanization, in the Western Minority Regions Group Conflict Events are on the rise. Especially since 2008, the Western Ethnic Regions Group Conflict Events occur frequently, resulting in extremely huge economic losses and political influence, severely affecting the social stability of minority areas and local economic and social development.

\section{B. Research Status}

Now, there are a lot of articles in our country about the factors of Urbanization Mass Incidents. Lu and Lo(2007) have pointed that, in the process of promoting urbanization, the nonagricultural rapidly highly concentrate in urban, caused direct conflicts in population and resources, energy, pollution, ecological and living environment; Due to speeding to adjust the economic structure, income distribution gap has increased, and the interest demands of some social groups can't be fulfilled, leading to the conflict events. Wang Zhiqiang(2012) have believed that reasons of Urbanization Mass Incidents include mechanisms, development pattern, reform and innovation-the systemic problems in the process of society.

There are different research methods to analyze Urbanization Mass Incidents, such as Socialist Contradiction Theory (Wang Xueliang, 2014), Quantitative Analysis (Fu Jun \& Chen Yao, 2015), Regression Analysis (Huang Dan \& Xu Dengyao, 2011) and other quantitative or qualitative or a combination of both methods. But there are not many scholars intensively studying on the reason, especially Urbanization Mass Incidents in the West National Areas. So the research based on Grounded Theory digging the key factors leading to the group events is very meaningful.

\section{THE CONCEPT OF GROUNDED THEORY}

When looking for reasons which induce the Western Minority Regions Group Events, only directly measured by quantitative methods will be very challenging, such as which indicators you want to set, how to obtain data, and a reliability of the data obtained and other issues. Qualitative research is through analyzing disordered information, finding out problems, understanding the phenomenon and exploring a topic of "why". And Grounded Theory is considered more formal and scientific method.

\footnotetext{
* Corresponding author
} 


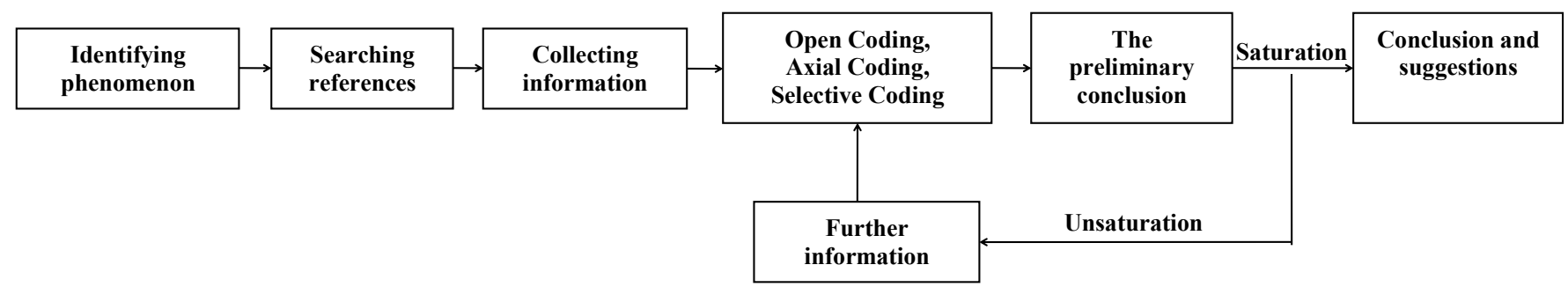

Fig. 1. The process of Grounded Theory

Grounded Theory starts directly from actual observations, summarizing the experience summarized from the original data and then rising to the theory of the system. This theory was first proposed in 1976, by the sociologists Glaser and Strauss. The use of a systematic program for the development of a phenomenon and the inductive guide the theoretical roots of qualitative research methods. Strauss defined the analysis of the information as coding, referring to the process which will collect or translate written materials to be decomposed, identify the phenomenon, conceptualize the phenomenon, then reabstracting concept, upgrading and integrating into the core category and key category in an appropriate manner. This process is to be faithful to the information, digging out the scope of information to identify the nature and dimensions of the nature of the scope. And the relationship between the scope of complex cross is the institute of theoretical obtained. The research process can be shown like this in Fig.1.

\section{ANALYSIS ON THE KEY FACTORS OF THE MASS INCIDENTS IN THE WESTERN MINORITY AREAS BASED ON THE GROUNDED THEORY}

\section{A. Data collection}

The method of grounded theory through a variety of channels, in the data collection process, according to investigation, interview and literature records, books, researcher, collect as detailed information, and pay attention to any details. The number of participants, the destructive force (impact), evolution speed events, coupling the secondary events and make measures to deal with the program, the length of time, the processing result as the main characterization system for major mass incidents, 2014 Jinning 2013 conflict, the conflict in Jinning, Chongqing Wansheng people gathered event, Sichuan Luzhou event, Yunnan Menglian incident, Guizhou Gansu Longnan Weng'an incident, events such as the western urbanization in Minority Areas group events typical case as the main object. Data were collected through the relevant media, by researchers such as oral direct and indirect channels, reducing events may live, for later work Make preparations.

\section{B. Open decoding}

Open coding that with an open mind, hanging set personal bias and the research community's opinion, all information according to their own nature present state to be named and belongs to the chemical process. For data information reflected in the phenomenon, through constant comparison for a concept label affixed to the phenomenon, then the similar concept to gather together, to dig out the more high level concepts, and define the nature and dimensions of category. Research process we follow grounded theory method of the native code principle and the causes in the western ethnic regions of events as the theme, of all relevant information in each case were verbatim initial coding and initial conceptualization, see TABLE I.

Through the open coding analysis on typical cases and information repeatedly finishing a 67 concept, and carries on the preliminary clustering, formed, including the time, place, group member source, endanger the basic survival, event frequency, direct stakeholders action, their action, conflict of interest, income levels, values, emotional crowd, gossip rumors, mental activity, improper disposal, the lack of leadership, weak sense of crisis, sluggish, lack of credibility, strong action, ethnic and religious culture, the concept of family, negative influence 22 categories.

\section{Axial coding}

Open coding analysis is independent of the scattered by category, their relationship has not been fully explored. The middle stage step by step grounded theory encoding process as the main encoding type, is the use of "causal conditions, phenomena, and context conditions, intermediary action / interaction strategy, the" a paradigm model. The opening of the decoding process together with category 4 , aims to find the main concept, establish category and concept between the secondary class of various organic connection. This requires us to detail information, the concept, category analysis, re integration of previously decomposed materials, focusing on logic correlation between various factors and interactions in promoting events in the evolution process, so that the main category of spindle formation decoding (see TABLE II).

\section{Selective Coding}

Selective coding is to get the a core category after systematic analysis of the categories, and link up other categories systematically to verify the relationship between them, so as to use the theoretical range including almost of the findings. The main tasks of the process are identifying the core category which can include all other categories, a brief description of all the phenomena by all of the categories and relationship the relationships, linking the core categories with others by special models which can verified by all of information, and continuing to develop the scope of a more subtle and comprehensive features. It can find out two core categories, formal and informal institutions, by continuing analysis of the eight main categories (Fig.2). 
TABLE I. OPEN CODING PROCESS OF TYPICAL CASE INFORMATION (EXCERPT)

\begin{tabular}{|c|c|}
\hline Case information & Conceptualization \\
\hline $\begin{array}{l}a_{1} \text { In October 14, 2014, Jincheng Jinning County of Kunming City, Pan Asia Industrial Products Trade and } \\
\text { logistics center in the process of project construction. }\end{array}$ & $a_{1}$ Scene \\
\hline $\begin{array}{l}\mathrm{a}_{2} \text { Four years to the village three times hit land. Due to the compensation, road construction and other issues, } \\
\text { the villagers and the government and project implementation is divided, repeatedly clashed. }\end{array}$ & $\mathrm{a}_{2}$ Contradiction accumulation \\
\hline $\begin{array}{l}\text { a } 3 \text { In order to prevent land was forced to requisition, rich near the village of villages in the uniting to protect. } \\
\text { They at least set up seven insurance duty point, guarded day and night. Three, Guangji and rich three villages, } \\
\text { because in Jin town northeast corner and villagers, like the northeast as brave and staunch, when the called "the } \\
\text { three northeastern provinces". }\end{array}$ & $\mathrm{a}_{3}$ Stakeholder rights approach is limited \\
\hline $\begin{array}{l}\text { a4 The other end of the road is a team of thousands of people. In the official notification, the identity of the } \\
\text { team is the construction personnel. They are armed with a variety of equipment, dressed in uniform clothing. }\end{array}$ & $\mathrm{a}_{4}$ Group membership \\
\hline as "Two villagers were killed, both melee was the other with a knife hacked tube" & as Strong party behavior \\
\hline $\begin{array}{l}\mathrm{a}_{6} 14 \text { days of conflict in her mouth there was another version of the text has not yet been introduced, the } \\
\text { woman suddenly hung up the phone. Once again call, the other said the wrong call, send text messages, there is } \\
\text { no response. }\end{array}$ & $\begin{array}{l}\text { a } 6 \text { Stakeholders do not actively } \\
\text { cooperate with the investigation or } \\
\text { deliberately conceal the truth }\end{array}$ \\
\hline $\begin{array}{l}\text { a7 Can't communicate directly with the villagers, to effectively resolve conflicts; to the grassroots } \\
\text { organizations, construction inspection, guidance, supervision and promotion is not in place. }\end{array}$ & $\begin{array}{l}\text { a7 Related government departments } \\
\text { dereliction of duty }\end{array}$ \\
\hline $\mathrm{a}_{8}$ Not in the first time rushed to the forefront of the fierce conflict, to take decisive measures to deal with. & $\mathrm{a}_{8}$ Crisis consciousness is weak \\
\hline $\begin{array}{l}\text { a9 Official notification of defects, key problems did not explain, and media reports contradict triggered a crisis } \\
\text { of confidence. Media of Jinning County land conflict event tracking reports and put forward many questions, } \\
\text { because the official yet to respond, public opinion, the rapid warming. }\end{array}$ & $\begin{array}{l}\text { a9 The government has not timely } \\
\text { published authoritative, accurate } \\
\text { information }\end{array}$ \\
\hline $\begin{array}{l}\mathrm{a}_{10} \text { The staff had responded that Jinning County Public Security Bureau Command Center for the first time the } \\
\text { villagers received the alarm is } 10 \text { in October 14th, 56, but the villagers said many times the police, the police } \\
\text { have not appeared in a timely manner. }\end{array}$ & $\mathrm{a}_{10}$ Police handling time delays \\
\hline $\begin{array}{l}a_{11} \text { In the disposal of the rescue process, the scene gradually gathered more people, all kinds of rumors since } \\
\text { four. }\end{array}$ & $\mathrm{a}_{11}$ Rumour \\
\hline $\begin{array}{l}\mathrm{a}_{12} \text { The incident will be briefly characterized as security incidents, repeated the power of police interference, } \\
\text { triggering a number of "group events", resulting in a serious loss. }\end{array}$ & $\mathrm{a}_{12}$ Abuse of police force \\
\hline
\end{tabular}

TABLE II. MAIN CATEGORY OF THE FORMATION OF THE MAIN SPINDLE DECODING

\begin{tabular}{|c|c|l|c|}
\hline $\begin{array}{c}\text { serial } \\
\text { number }\end{array}$ & fundamental category & Category of influence relation & Relationship connotation \\
\hline $\mathbf{1}$ & Trigger event & $\begin{array}{l}\text { Occurrence time, location, direct } \\
\text { stakeholder action, relative action }\end{array}$ & $\begin{array}{c}\text { The formation of a common scene of the crowd to stimulate } \\
\text { the crowd }\end{array}$ \\
\hline $\mathbf{2}$ & Social structure & Income level, value view & $\begin{array}{c}\text { Uneven distribution of social resources, there are still social } \\
\text { contradictions }\end{array}$ \\
\hline $\mathbf{3}$ & $\begin{array}{c}\text { Common view of } \\
\text { consensus }\end{array}$ & $\begin{array}{l}\text { Conflict of interest, the basic survival of the } \\
\text { endangered }\end{array}$ & $\begin{array}{c}\text { Common belief in the existence of the interests of the } \\
\text { situation }\end{array}$ \\
\hline $\mathbf{4}$ & Group member & $\begin{array}{l}\text { Group member origin, group emotion, } \\
\text { psychological activity }\end{array}$ & $\begin{array}{c}\text { Sources of different, the role of different; interaction in the } \\
\text { emotional planning and the crowd's psychological } \\
\text { motivation }\end{array}$ \\
\hline
\end{tabular}


Table II, cont.

\begin{tabular}{|c|c|c|c|}
\hline 5 & The image of government & $\begin{array}{l}\text { Improper disposal, lack of leadership, weak } \\
\text { sense of crisis, sluggish, lack of credibility }\end{array}$ & $\begin{array}{l}\text { Through the implementation of the policy, the way to deal } \\
\text { with the disposal of the right or not, the timeliness and } \\
\text { authority of the public information and its only } \\
\text { performance, the evaluation of the government }\end{array}$ \\
\hline 6 & public opinions & Rumour & $\begin{array}{l}\text { Through the traditional, modern media to spread the news, } \\
\text { including accurate and accurate }\end{array}$ \\
\hline 7 & $\begin{array}{l}\text { Ethnic and religious } \\
\text { culture }\end{array}$ & $\begin{array}{l}\text { National culture, religious culture, family } \\
\text { concept }\end{array}$ & National culture, traditional customs, family tradition, etc. \\
\hline 8 & "Three forces" & $\begin{array}{l}\text { Religious extremism, violent terrorist forces, } \\
\text { ethnic separatist forces }\end{array}$ & $\begin{array}{l}\text { Influence the social harmony and the extreme power of } \\
\text { national unity }\end{array}$ \\
\hline
\end{tabular}

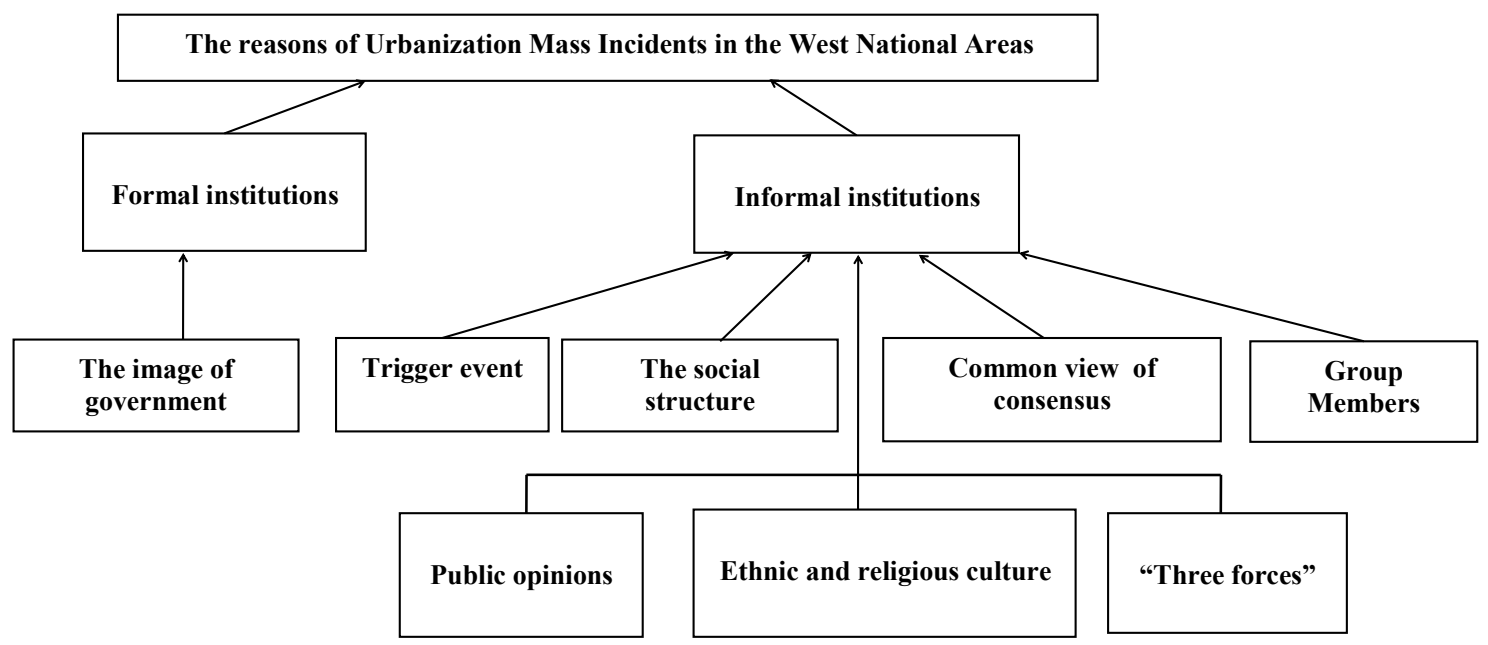

Fig. 2. The Selective Coding of the Attribution of Urbanization Mass Incidents in the West National Areas

Formal institutions refers to written regulations, including policy made by State or Local Government, regulations, laws and regulations; the informal institutions contains all except the formal institutions, including the value of beliefs, customs, traditional culture, ethics and so on. Thus the image of government belongs to the category of formal institutions, and informal institutions contain the remaining seven areas. Based on this, when the government resolves Urbanization Mass Incidents in the West National Areas, they should, on one hand regulate the duties without slow action and chaos, actively promote the implementation of relevant policies, research the fact of life of the public, and satisfy the public's requirements by serving the people wholeheartedly; on the other hand, pay attention to the role of human behavior, ideas, values, etc., promote positive thinking, and correct the negative thoughts to the right track by the use of "human" based approach.

\section{CONCLUSION}

Grounded Theory is used more widely in the field of sociology than the field of management. Using Grounded Theory to resolve Urbanization Mass Incidents in the West National Areas is a breakthrough to the conventional methods, helping to dig out the deeper reasons. However, whether conceptualization is accurate, the concepts can be fully covered in categories, all categories and main categories are included in the main models, are should be resolved by using Grounded
Theory. According open coding, Open Coding, Axial Coding, Selective Coding, the factors that we can draw Western Minority Areas Urbanization Mass Events can be grouped into eight main categories, which can be grouped into two core categories, namely formal and informal institutions. And formal institutions include the Image of the Government, the remaining seven belonging to the informal institutions.

The main and core categories, analyzed by using Grounded Theory to research Urbanization Mass Events in the West National Areas, provide the Government the direction on deal with some events. Put importance on aspirations from the public and deal with in correct manners, so that the masses have a place to relieve the pain to avoid sponsoring group events. When the Mass Events occur, they should handle timely without slow action to control events. Meanwhile they should publish the correct official news and identify the problem as soon as possible. Also they should promote positive thinking, stopping the spread of harmful ideology and culture.

\section{ACKNOWLEDGMENT}

This paper is an initial achievement of National Natural Science Fund Project, Study on the Characteristics and Institutional Join Force of the Urbanization Mass Incident in the West National Areas. The project approval number is 71463063 . 
First of all, I would like to extend my sincere gratitude to my tutor, Associate Professor Yang Ying, for her instructive advice and useful suggestions on my paper. I am deeply grateful for her help in the completion of this paper. Without her consistent and illuminating instruction, I can't make it successfully. Secondly, I would like to thank deeply all the other teachers and classmates in Management Studies for their direct and indirect guidance and help to me.

\section{REFERENCES}

[1] J. Fu, and Y. Chen, "The Analysis of Reasons and the Study of Measures of Environmental Group Events in PX Project," Environmental Protection, vol. 16, 2015.

[2] D. Huang and D.Y. Xu, "The Study on the Relationship between Population Growth and Land Urbanization by SPSS in Nanchong," vol. 01, The World \& Chongqing, 2011, pp.76-78.
[3] B.X. Li, "The Construction of Response Capacity for Group Events of Western National Region Local Government," Tianjin: Zhou Enlai School of Government, Nankai University, 2014.

[4] Z.G. Li, and X.W. Li, "Applying Grounded Theory in the Models and Determinants Study of Mengniu's Fast Growth," vol. 19, Management Sciences in China, 2006, pp. 3-7.

[5] W.M. Lu, and S.F. Lo, "A closer look at the economic-environmental disparities for regional development in China European," Journal of Operational Research, 2007, pp. 882-894.

[6] A. Strauss, and J. Corbin, "Grounded Theory Methodology: An Overview," Handbook of Qualitative Research Thousand Oaks Sage Publications, 1994.

[7] Z.Q. Wang, and Z.C. Peng, "The Study on Emergency Management Mechanism of Social Group Events," Chinese Public Administration, vol. 07, 2012, pp.70-76.

[8] X.L. Wang, "The Study on Group Events based on Socialist Contradiction Theory," Beijing: Party School of the Central Committee of CPC, 2014

[9] L.Y. Xiang, "Influencing Factors in Evolution of Major Group Events- a Study Based on the Grounded Theory," Journal of Intelligence, vol. 31, 2012, pp. 64-69. 